\title{
Vertical distribution of juvenile Pacific cod Gadus macrocephalus: potential role of light, temperature, food, and age
}

\author{
M. W. Davis*, M. L. Ottmar \\ NOAA Fisheries, Alaska Fisheries Science Center, Fisheries Behavioral Ecology Program, Hatfield Marine Science Center, \\ 2030 S. E. Marine Science Dr., Newport, Oregon 97365, USA
}

\begin{abstract}
Prior to the present study little was known about factors that control daily, seasonal, or ontogenetic changes in the vertical distribution of Pacific cod Gadus macrocephalus, an ecologically and commercially important fish species in the northern Pacific Ocean. Vertical distribution and migration of species in the family Gadidae are primarily controlled by gradients of light, temperature, food, and predators. The role of these factors in the vertical distribution of juvenile Pacific cod $(0+$ and $1+\mathrm{yr}$ ) was tested by exposing fish to vertical gradients of light, temperature, and food that were constructed in the laboratory to simulate conditions normally found in Pacific cod habitats. Fish avoided high light and cold water. Food introduction in warm isothermal water $\left(9^{\circ} \mathrm{C}\right)$ induced fish to feed and form more groups than when food was not present. In cold-thermocline conditions $\left(9\right.$ to $3^{\circ} \mathrm{C}$, top to bottom), food introduction into the lower third of the tank induced fish to swim deeper, but detections of food, feeding, and the formation of groups were initially inhibited by excursions into cold water. Increasing consumption of food during the hour after feeding indicated that fish adapted to cold water. Fish adapted within an hour of continuous exposure to high light as they swam higher in the water column. The effects of fish age were minor and evident as interactions with environmental condition effects on the number of fish groups. Pacific cod are able to adapt to changing ecological conditions, and their behavioural flexibility in response to food, temperature, and light conditions make prediction of vertical distribution complex. Future field studies of the diel vertical migration of Pacific cod should include concurrent measurements of key environmental factors and consider the ability for fish to quickly adapt to changing conditions.
\end{abstract}

KEY WORDS: Behavioural adaption · Diel vertical migration $\cdot$ Feeding $\cdot$ Shoaling $\cdot$ Stratification · Thermal habitat

Resale or republication not permitted without written consent of the publisher

\section{INTRODUCTION}

Members of the family Gadidae are important components of ocean ecosystems and commercially harvested fish stocks. The vertical distribution of gadoid fishes can be an important aspect of their ecology, life history, and commercial exploitation. Vertical distribution in juvenile and adult stages, often resulting from diel vertical migration (DVM), is controlled by behavioural responses to environmental factors within the constraints of physiological capabilities (Neilson \& Perry 1990, Stensholt et al. 2002). Gadoid larvae have limited swimming capabilities and undergo DVM as an efficient means for access to ocean depths with abundant food, reduced predator encounters, and current speeds and directions for favourable horizontal transport (Olla et al. 1996, Fiksen et al. 2007). Fish surveys and fishing operations can be affected by DVM, since capture relies in part on the intersection of fish and fishing gear, and survey acoustic detection can be biased as fish make excursions into and out of the acoustic dead zone near the bottom (Aglen et al. 1999, Neilson et al. 2003).

Pacific cod Gadus macrocephalus is an important species in North Pacific Ocean ecosystems. Pacific cod 
fisheries have recently increased, representing the second most important Alaska ground fishery in amount and value (Laurel et al. 2007, Conners \& Munro 2008). Fisheries for Pacific cod in Alaska waters have occurred for over $4500 \mathrm{yr}$, and populations appear to be resilient and able to recover from environmental perturbations that have occurred during that period, including increased water temperature (Maschner et al. 2008). Future effects of increased temperature may include interactions of temperature and fishing effort, as fish might remain longer in shelf habitats and become more susceptible to capture (Ciannelli \& Bailey 2005). Pacific cod can be highly mobile, with populations undergoing annual migrations (Shimada \& Kimura 1994, Connors \& Munro 2008). In the Bering Sea fish are on the shelf during the summer $(<30$ to $100 \mathrm{~m}$ depth), moving to the outer shelf in the fall ( $>100$ to $200 \mathrm{~m}$ depth), off the shelf in the winter $(>200 \mathrm{~m}$ depth), and finally aggregating in spawning areas in late winter. Pacific cod mobility exposes fish to vertical gradients of light, temperature, food, and predators as they range over different depths associated with season- and age-induced changes in habitat (Ciannelli \& Bailey 2005, Abookire et al. 2007, Laurel et al. 2007). Juvenile Pacific cod are generally found at temperatures ranging from 0 to $9^{\circ} \mathrm{C}$ and light levels of darkness of $80 \mu \mathrm{mol}$ photons $\mathrm{m}^{-2} \mathrm{~s}^{-1}$ (Ciannelli \& Bailey 2005, Laurel et al. 2009).

Little is known about the effects of environmental factors on the vertical distribution and patterns of DVM in Pacific cod. The goal of the present study was to test juvenile fish responses to laboratory-simulated vertical gradients of light, temperature, and food conditions, and the interactions that are normally found in Pacific cod habitats. Laboratory conditions can only simulate field conditions in a general way and are not meant to be direct tests for field fish distributions. Testing of fish responses in the laboratory are a necessary first step for identifying important factors that control behaviour and vertical distribution and to demonstrate fish capabilities and the possible effects of factor interactions (Sogard \& Olla 1993, Olla et al. 1996). Results from laboratory studies can then be used to formulate hypotheses that can be tested in the field. Understanding the roles of environmental factors in controlling the DVM of Pacific cod are important parts of modelling their spatial and temporal distributions and ecology and for assessing the impacts of DVM on surveys of fish abundance and distributions.

\section{MATERIALS AND METHODS}

Collection and rearing of juvenile fish. Pacific cod Gadus macrocephalus were collected as young of the year (30 to $50 \mathrm{~mm}$ total length, TL) using a beach seine during July 2006 and July 2007 near Kodiak, AK, USA $\left(57^{\circ} 43^{\prime} \mathrm{N}, 124^{\circ} 31^{\prime} \mathrm{W}\right)$ and transported by air to the laboratory in Newport, OR, USA. Fish were reared for up to $1 \mathrm{yr}$ in $2510 \mathrm{l}$ circular tanks (2.0 m diameter and $0.8 \mathrm{~m}$ depth) supplied with flowing sand-filtered seawater (8 to $10^{\circ} \mathrm{C}, 30$ to $32 \mathrm{ppt}$ salinity) and low-light conditions ( 0.5 to $1.5 \mu \mathrm{mol}$ photons $\mathrm{m}^{-2} \mathrm{~s}^{-1}$ ). Fish were fed to satiation 3 times per week with pelleted cod food.

Experimental thermocline tanks. Experiments were conducted in 2 tanks of $15000 \mathrm{l}$ volume $(2.5 \mathrm{~m}$ depth, $2.5 \mathrm{~m}$ width, and $2.5 \mathrm{~m}$ breadth) in which thermoclines could be constructed (see Olla \& Davis 1990, Sogard \& Olla 1993 for detailed descriptions of the thermocline tanks). Tanks were constructed with a fibreglass bottom and sides and an acrylic viewing window in the front. Thermistors were embedded in a side wall of the tank at $15 \mathrm{~cm}$ depth intervals to continuously measure water column temperature. A partition divided the tank into equal-sized front and rear sections to more easily observe small fish that were placed in the front section. A false PVC bottom was drilled with a grid of $5.0 \mathrm{~mm}$ holes (spaced $3.8 \mathrm{~cm}$ apart) through which seawater $\left(9^{\circ} \mathrm{C}\right)$ was introduced into the tank bottom and out through surface drains. To form a thermocline, chilled seawater $\left(0.5^{\circ} \mathrm{C}\right)$ was introduced through the bottom over a 50 min period, with warmer water leaving the tank from surface drains (Fig. 1). After the thermocline was formed, the water flow was stopped and the temperature gradient remained stable for $24 \mathrm{~h}$. Five similarly sized fish formed a replicate assemblage that was placed into an experimental tank and acclimated for $48 \mathrm{~h}$ in isothermal $\left(9^{\circ} \mathrm{C}\right)$ conditions and a $12 \mathrm{~h}$ light:12 $\mathrm{h}$ dark photoperiod, with low light of 33.0 to $8.9 \mu \mathrm{mol}$ photons $\mathrm{m}^{-2} \mathrm{~s}^{-1}$, ranging from top to bottom and supplied by a $400 \mathrm{~W}$ metal halide lamp

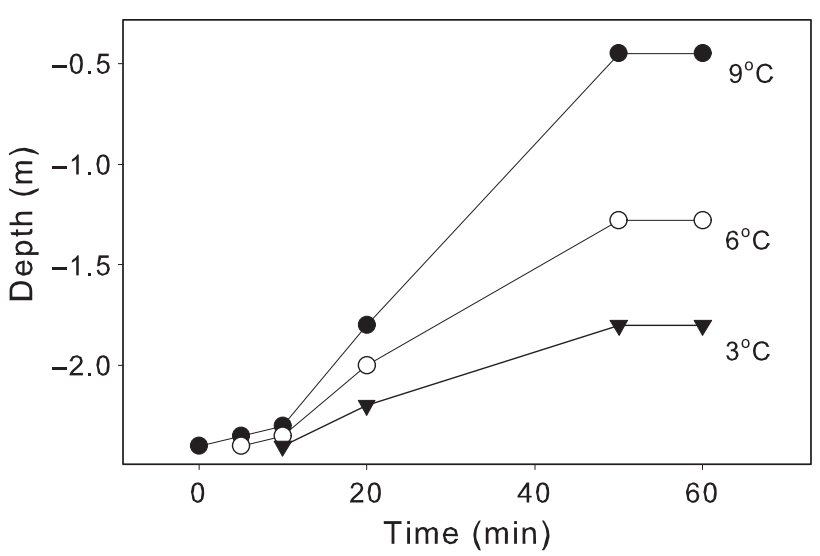

Fig. 1. Temperature profiles in a thermocline tank as $0.5^{\circ} \mathrm{C}$ seawater was pumped into the tank through the bottom over a $50 \mathrm{~min}$ period. Lines indicate depths $(\mathrm{m})$ for $9^{\circ} \mathrm{C}(\bullet), 6^{\circ} \mathrm{C}(\mathrm{O})$, and $3^{\circ} \mathrm{C}(\mathbf{v})$ 
(6000 K colour temperature). Fish were not fed during the acclimation period.

Experiments with changing environmental conditions. After acclimation in the experimental tank, independent replicate subjects (assemblages of 5 similarly sized fish) of age $0+(7.0$ to $8.8 \mathrm{~cm} \mathrm{TL})$ or $1+(13.6$ to $18.9 \mathrm{~cm}$ TL) were observed during a temporal series of experimental treatments that were designed to simulate the normal range of conditions in Pacific cod habitat (see 'Introduction'). Experiments were divided into 2 parts, based on the logistical constraints of sequential exposures to changing environmental conditions during a limited day length (Table 1). The primary difference between the 2 parts was that fish were fed under low light or fed under high light. Food (pelleted cod food) was introduced through a tube so that it appeared and was available to fish in the lower third of the tank. Pelleted food was used as a standardized food stimulus to eliminate variability associated with live prey. Although pelleted food is not a natural prey, it was readily eaten by Pacific cod and it supplied complete nutrition for normal growth. Experiments included alternation of low and high light to test responses to rapidly changing light conditions and alternation of warm-isothermal and cold-thermocline conditions to test responses to vertical thermal gradients. The low-light condition was the ambient light in the tank (33.0 to $8.9 \mu \mathrm{mol}$ photons $\mathrm{m}^{-2} \mathrm{~s}^{-1}$, top to bottom). High light (286.5 to $48.7 \mu \mathrm{mol}$ photons $\mathrm{m}^{-2} \mathrm{~s}^{-1}$, top to bottom) was produced by turning on 2 additional $1000 \mathrm{~W}$ halogen lamps $\left(5300^{\circ} \mathrm{K}\right.$ colour temperature) above the tank. Temperature changes included alternation between isothermal $\left(9^{\circ} \mathrm{C}\right)$ and thermocline $(9$ to $3^{\circ} \mathrm{C}$, top to bottom) states. In the field, light conditions rapidly change as cloud cover or sun angle changes. Fish detect rapid changes in temperature as they migrate through thermoclines that may be seasonally produced and dissolved.

These laboratory tests did not simulate actual field conditions, as tanks were small and shallow relative to the open ocean. Tanks were large enough for fish to swim freely and form and dissolve groups in response to changing environmental conditions. Responses of fish in the laboratory demonstrate their capabilities rather than their actual responses in the field. The tests were designed to determine the relative importance of temperature, light, and food in controlling fish behaviour and distributions and to guide formulation of hypotheses for testing the role of environmental factors in control of vertical fish distributions in the field, where the isolated effects of factors often cannot be identified.

Observations of Pacific cod behaviour. Responses of a replicate subject (fish assemblage) to an environmental condition were observed from behind a blind
Table 1. Gadus macrocephalus. Protocol for exposure of subjects (fish assemblages composed of groups of 5 fish) in warm isothermal $\left(9^{\circ} \mathrm{C}\right)$ and cold thermocline $\left(9\right.$ to $3{ }^{\circ} \mathrm{C}$, top to bottom) conditions to low-light conditions (33.0 to $8.9 \mu \mathrm{mol}$ photons $\mathrm{m}^{-2} \mathrm{~s}^{-1}$, top to bottom), high-light conditions (286.5 to $48.7 \mu \mathrm{mol}$ photons $\mathrm{m}^{-2} \mathrm{~s}^{-1}$, top to bottom), and food (introduced into lower third of the tank). Because of the logistics of exposing fish to multiple sequential changes in environmental conditions during limited day length, experiments were conducted in 2 parts with feeding in low light in the first part and feeding in high light in the second part. For both ages $(0+$ and $1+\mathrm{yr}$ ) each part tested 8 independent replicate subjects. Responses of subjects to 17 environmental conditions in Part 1 experiments and 18 environmental conditions in Part 2 experiments were observed and pooled for the analysis of variance

\begin{tabular}{|c|c|c|}
\hline Day & Time od day & Environmental condition \\
\hline \multicolumn{3}{|c|}{ Part 1: Low-light feeding experiments } \\
\hline \multirow[t]{2}{*}{1} & 08:00 & $\begin{array}{l}\text { Subject acclimation, } 5 \text { fish were } \\
\text { introduced into isothermal tank } \\
\text { with low light and no food present }\end{array}$ \\
\hline & 20:00 & Low light off \\
\hline \multirow[t]{2}{*}{2} & 08:00 & Low light on \\
\hline & 20:00 & Low light off \\
\hline \multirow[t]{4}{*}{3} & 08:00 & Low light on \\
\hline & $10: 00$ & High light on \\
\hline & $10: 30$ & Low light on \\
\hline & 20:00 & Low light off \\
\hline \multirow[t]{6}{*}{4} & 08:00 & Low light on \\
\hline & 11:00-11:50 & Thermocline introduced \\
\hline & $12: 30$ & High light on \\
\hline & $13: 00$ & Low light on \\
\hline & $13: 30$ & Food introduced \\
\hline & 20:00 & Low light off \\
\hline \multirow[t]{4}{*}{5} & 08:00 & Low light on \\
\hline & 09:45-11:00 & $\begin{array}{l}\text { Thermocline drained, tank refilled } \\
\text { with isothermal water }\end{array}$ \\
\hline & $13: 30$ & Food introduced \\
\hline & $20: 00$ & Low light off \\
\hline 6 & 08:00 & $\begin{array}{l}\text { Low light on, fish taken out } \\
\text { of the tank and measured for total } \\
\text { length }\end{array}$ \\
\hline \multicolumn{3}{|c|}{ Part 2: High-light feeding experiments } \\
\hline \multirow[t]{2}{*}{1} & $08: 00$ & $\begin{array}{l}\text { Subject acclimation, } 5 \text { fish were } \\
\text { introduced into isothermal tank } \\
\text { with low light and no food present }\end{array}$ \\
\hline & 20:00 & Low light off \\
\hline \multirow[t]{2}{*}{2} & 08:00 & Low light on \\
\hline & 20:00 & Low light off \\
\hline \multirow[t]{4}{*}{3} & 08:00 & Low light on \\
\hline & $12: 30$ & High light on \\
\hline & $15: 30$ & Low light on \\
\hline & 20:00 & Low light off \\
\hline \multirow[t]{6}{*}{4} & 08:00 & Low light on \\
\hline & 11:00-11:50 & Thermocline introduced \\
\hline & $12: 30$ & High light on \\
\hline & $15: 10$ & Food introduced \\
\hline & $15: 30$ & Low light on \\
\hline & 20:00 & Low light off \\
\hline \multirow[t]{6}{*}{5} & 08:00 & Low light on \\
\hline & 09:45-11:00 & $\begin{array}{l}\text { Thermocline drained, tank refilled } \\
\text { with isothermal water }\end{array}$ \\
\hline & $12: 30$ & High light on \\
\hline & $15: 10$ & Food introduced \\
\hline & $15: 30$ & Low light on \\
\hline & 20:00 & Low light off \\
\hline 6 & 08:00 & $\begin{array}{l}\text { Low light on, fish taken out } \\
\text { of the tank and measured for total } \\
\text { length }\end{array}$ \\
\hline
\end{tabular}


and recorded once per minute for 5 min after a change in conditions or at a specified sampling time (see Table 1). Responses to an environmental condition were summed for an assemblage over the 5 min observation period to calculate a mean response for each replicate subject, which was then used for statistical analysis. Mean subject dependent response variables included vertical position (depth), number of fish groups (a group consisted of fish within 1 body length of 1 or more fish), and number of fish observed feeding during a 5 min period after food introduction. Part 1 and Part 2 experiments (see Table 1) each used 8 independent subjects for each age, making a total of 32 replicate subjects. For statistical analysis, subjects from Part 1 and Part 2 experiments were linked to form a continuum of 8 replicates for each age through all 35 environmental conditions. A total number of 160 fish was used in experiments, and no fish was used in $>1$ assemblage.

Statistical analysis. Testing for the overall effects of isolated predictor variables and their interactions (temperature, light, food, and age) required a 4-way repeated-measures analysis of variance (ANOVA), which was not possible to interpret, given that there were many higher order interactions. Therefore, the predictor variable 'environmental conditions' was formed to include all combinations of light, temperature, and food conditions, and then 2-way repeatedmeasures ANOVA was used to test for the overall effects of age and environmental conditions. Repeated-measures ANOVA is a widely accepted analysis method that originated in psychology and, subsequently, was extended into experimental biology (Hicks 1982, Sogard \& Olla 1996, Ryer et al. 2008). In typical statistical calculation programs for repeatedmeasures ANOVA, terms in the analysis include subject and within-subject and between-subject factors. The subject in the ANOVA was a replicate fish assemblage and the effects of between-subject (age) and within-subject (environmental conditions) predictor variables and their interactions were determined. Effects on 3 dependent response variables, including mean fish depth, number of groups, and number of fish feeding were analyzed separately. A subject (replicate fish assemblage) was repeatedly observed during an experiment, and mean responses of depth and number of groups to 35 environmental conditions (see Table 1) were calculated for each of 8 subjects in each age group $(0+$ and $1+y r)$ and used in the ANOVA. For number of fish feeding, mean responses to 4 feeding conditions (see Table 1) were calculated for each of 8 subjects in each age group and were used in the ANOVA. Statistical significance was considered at $p<0.05$, and differences in mean response variables among environmental conditions and between ages were determined with the Tukey honestly significant difference method for post hoc multiple comparisons. All calculations were performed using Statistix 8.0, according to the generally accepted use of repeatedmeasures ANOVA models (Hicks 1982).

\section{RESULTS}

Mean depth of juvenile Pacific cod Gadus macrocephalus and number of fish feeding were controlled by environmental conditions, while for mean number of groups there were significant interactions between environmental conditions and age effects (ANOVA; Table 2). Significant differences among means for depth, number of groups, and number of fish feeding associated with changes in environmental conditions and age were identified using multiple comparisons and are discussed below.

Table 2. Gadus macrocephalus. A 2-way repeated-measures ANOVA was used to test for the overall effects of betweensubject (age: 0+ and 1+ yr) and within-subject (environmental conditions: changes in temperature, light, and food) predictor variables and their interactions. The dependent response variables mean fish depth (m), number of groups, and numbers of fish feeding were examined separately. See 'Materials and methods' section for description of experimental protocol. For fish depth and number of groups, 8 replicate subjects (fish assemblages) were observed in 35 environmental conditions for each age (see Table 1). For number of fish feeding, 8 replicate subjects (fish assemblages) were observed in 4 feeding conditions for each age (see Table 1). Error terms for between-subject (age) and within-subject (conditions) effects are indicted in the predictor variable column

\begin{tabular}{|lccc|}
\hline Source & df & $F$ & $p$ \\
\hline Fish depth (m) & & & \\
Age & 1 & 0.34 & 0.567 \\
Age $\times$ Subject error & 14 & & \\
Conditions & 34 & 18.26 & 0.000 \\
Age $\times$ Conditions & 34 & 1.33 & 0.103 \\
Age $\times$ Subject $\times$ Conditions error & 476 & & \\
Total & 559 & & \\
Number of groups & & & \\
Age & 1 & 0.68 & 0.423 \\
Age $\times$ Subject error & 14 & & \\
Conditions & 34 & 6.77 & 0.000 \\
Age $\times$ Conditions & 34 & 2.54 & 0.000 \\
Age $\times$ Subject $\times$ Conditions error & 476 & & \\
Total & 559 & & \\
Number of fish feeding & & & \\
Age & 1 & 0.02 & 0.891 \\
Age $\times$ Subject error & 14 & & \\
Conditions & 3 & 99.58 & 0.000 \\
Age $\times$ Conditions & 3 & 0.41 & 0.748 \\
Age $\times$ Subject $\times$ Conditions error & 42 & & \\
Total & 63 & & \\
\hline
\end{tabular}




\section{Effects of switching from low light to high light when food was not present}

Fish of both ages swam deeper after 1 min exposure to high light in isothermal conditions or thermocline conditions when food was not present (Fig. 2). No changes in the number of groups were associated with exposure to high light when food was not present.

\section{Adaption to high light when food was not present}

Fish of both ages swam deeper after 1 min exposure to high light and then swam into shallow depths at 30 and 60 min after the start of a period of continuous exposure to high light in isothermal conditions (Fig. 3). A similar pattern was shown in thermocline conditions, but was not significant. No changes in the number of groups were evident during $1 \mathrm{~h}$ of exposure to high light in isothermal or thermocline conditions.

\section{Effects of food presence in warm-isothermal conditions}

When food was present in the lower third of the tank, older fish swam deeper in low-light isothermal conditions (Fig. 4). Fish of both ages formed more groups in low-light or high-light isothermal conditions when food was present.

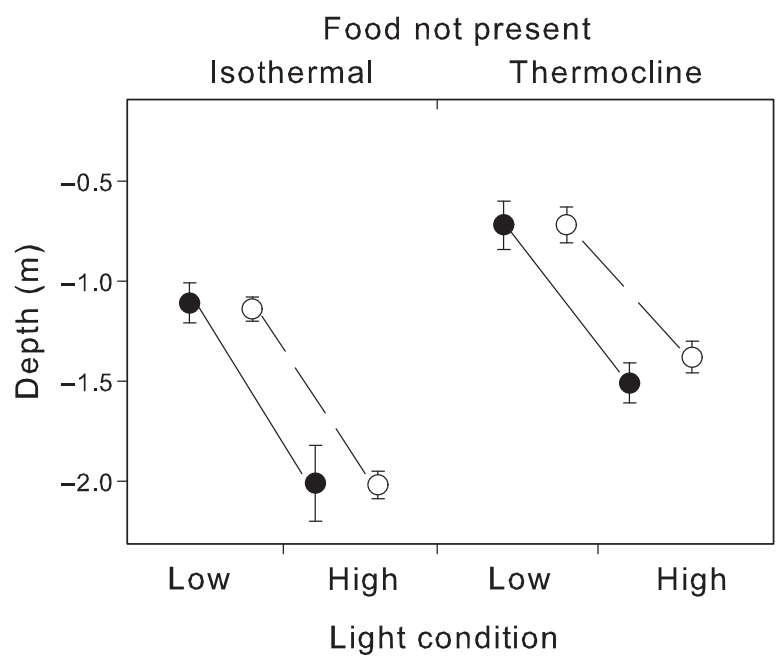

Fig. 2. Gadus macrocephalus. Depth changes in 0+ (•) and 1+ (O) yr fish occurring 1 min after switching from low light (Low) to high light (High) in warm isothermal $\left(9^{\circ} \mathrm{C}\right)$ or cold thermocline $\left(9\right.$ to $3^{\circ} \mathrm{C}$, top to bottom) conditions when food was not present. Values are mean $\pm 1 \mathrm{SE}$

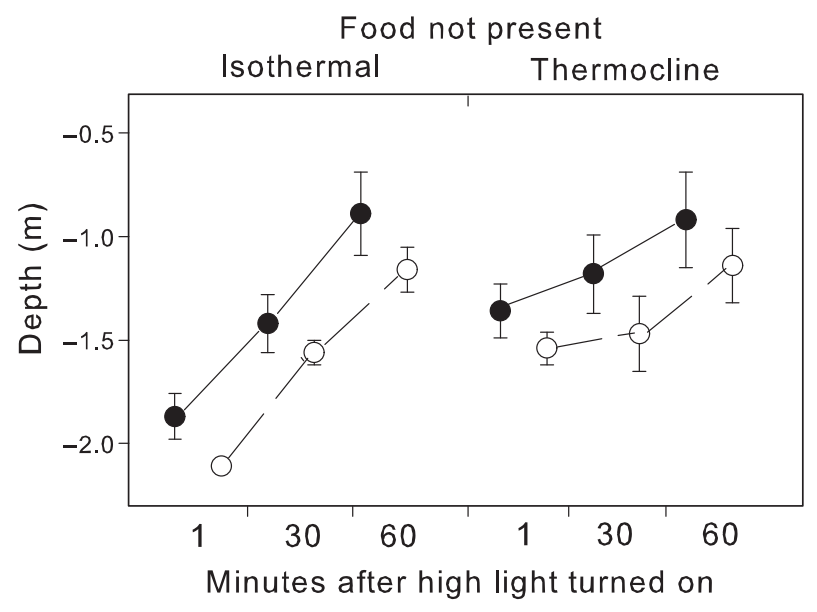

Fig. 3. Gadus macrocephalus. Adaptation to continuous high light by $0+(\bullet)$ and $1+(0)$ yr fish. Depth $(\mathrm{m})$ is shown at times (min) after high light was turned on in warm isothermal $\left(9^{\circ} \mathrm{C}\right)$ and cold thermocline $\left(9\right.$ to $3^{\circ} \mathrm{C}$, top to bottom) conditions when food was not present. Values are mean \pm 1 SE. Point without error bars includes $1 \mathrm{SE}$ within its diameter
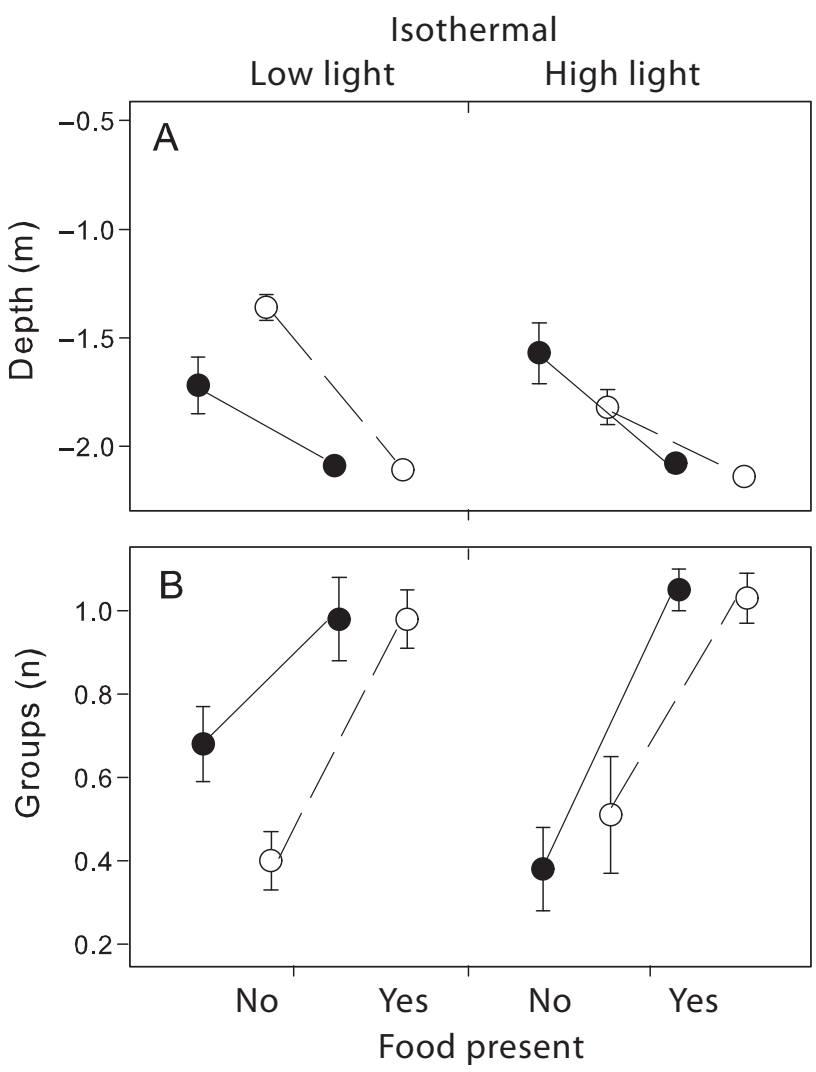

Fig. 4. Gadus macrocephalus. Effects of food introduction on 0+ $(\bullet)$ and $1+(0) \mathrm{yr}$ fish in warm isothermal $\left(9^{\circ} \mathrm{C}\right)$ conditions. Conditions were switched from no food low light to food presence in low light or no food high light to food presence in high light. Responses by fish included changes in: (A) depth (m) and (B) number of groups. Values are mean \pm 1 SE. Points without error bars include $1 \mathrm{SE}$ within their diameter 

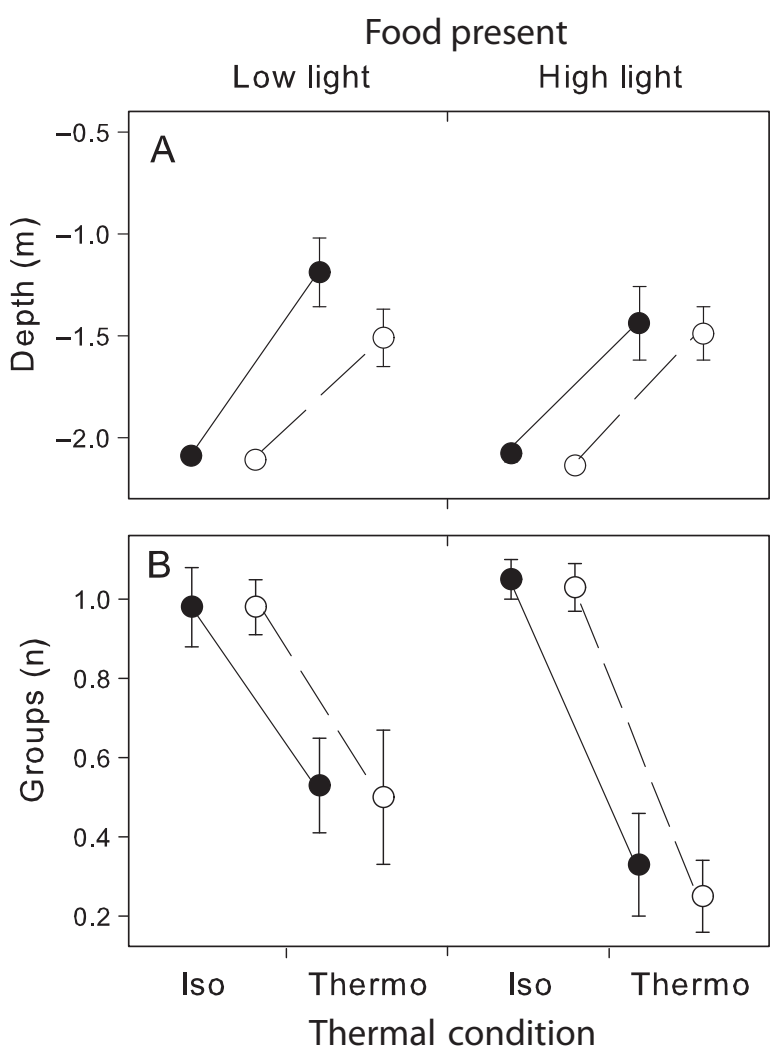

Fig. 5. Gadus macrocephalus. Effects on $0+(\bullet)$ and $1+(0) \mathrm{yr}$ fish of switching from warm-isothermal (Iso) to cold-thermocline (Thermo; 9 to $3^{\circ} \mathrm{C}$, top to bottom) conditions in low light or high light in the presence of food. In isothermal conditions, food was in $9^{\circ} \mathrm{C}$ water and, in thermocline conditions, food was in $3^{\circ} \mathrm{C}$ water. Responses by fish included changes in: (A) depth $(\mathrm{m})$ and $(\mathrm{B})$ number of groups. Values are mean $\pm 1 \mathrm{SE}$. Points without error bars include 1 SE within their diameter

\section{Effects of switching from warm to cold conditions when food was present}

Fish of both ages swam deeper in warm-isothermal conditions than in cold-thermocline conditions in low light or high light when food was present (Fig. 5). Fish of both ages formed more groups in isothermal conditions than in thermocline conditions in low light or high light when food was present.

\section{Effects of cold water on number of fish feeding}

Higher numbers of both ages of fish fed within 5 min of food introduction in low-light or high-light warm-isothermal conditions than in low- or high-light cold-thermocline conditions (Fig. 6). Increasing consumption of food during the hour after feeding in thermocline conditions indicated that fish adapted to cold water.

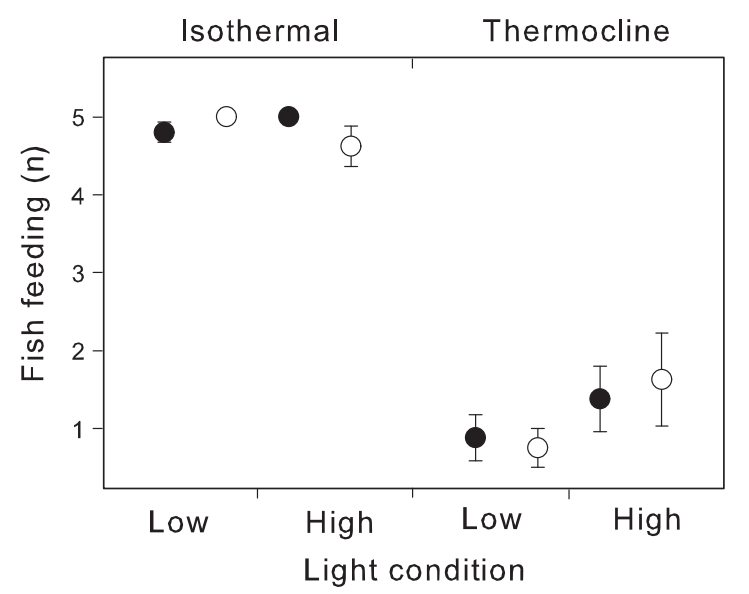

Fig. 6. Gadus macrocephalus. Effects of water temperature and light conditions on the number of $0+(\bullet)$ and $1+(0)$ yr fish feeding in low light (Low) or high light (High) in warmisothermal $\left(9^{\circ} \mathrm{C}\right)$ or cold-thermocline $\left(9\right.$ to $3^{\circ} \mathrm{C}$, top to bottom) conditions. Values are mean \pm 1 SE. Points without error bars include $1 \mathrm{SE}$ within their diameter

\section{DISCUSSION}

Fish responses to environmental factors that result in changes in vertical distribution, generally considered DVM, can be important aspects of fish ecology contributing to our understanding of distributions, feeding, growth, reproductive patterns, and interactions with predators. DVM in gadoid fishes primarily occurs in response to patches of food and predators, thermal gradients, and light conditions (Neilson \& Perry 1990, Strand \& Huse 2007). Pacific cod Gadus macrocephalus responded to thermocline conditions, alternation of low and high light, and the presence or absence of food. Primary DVM responses of gadoids may be modified by many other factors that were not tested in the present study. Hydrostatic pressure and acclimation determine the upper and lower limits of short-term vertical movements (Arnold \& Walker 1992, Stensholt et al. 2002). Fish condition, e.g. age, feeding history, reproductive state, and adaption to changing environmental conditions, controls vertical distribution (Sogard \& Olla 1996, Neilson et al. 2003, Cote et al. 2004). Physical factors, e.g. tide, current speed, salinity, and $\mathrm{O}_{2}$ concentration, may set physiological limits to the range of vertical movement (Stensholt et al. 2002, Strand \& Huse 2007).

Gadoid responses to factors controlling vertical distribution are variable and difficult to predict in the field, in part because of numerous interactions of controlling environmental factors and changing behavioural motivation to feed, avoid predators, and migrate. Several types of group responses have been identified, i.e. shallow water versus deep water, or 
resident versus migratory fish (Pálsson \& Thorsteinsson 2003, Hobson et al. 2007). These group responses can introduce bias into fishing operations and surveys that occur over wide depth ranges and alternating day and night conditions (DeBlois \& Rose 1995, Aglen et al. 1999).

Prior to the present study, little was known about the vertical distributions of Pacific cod or the factors that control the distribution of this species (Ciannelli \& Bailey 2005, Nichol et al. 2007, von Szalay et al. 2007). Pacific cod movements observed in the present laboratory study generally confirmed previously observed effects of light, temperature, and food distribution on vertical distribution, and the formation of groups in other gadoid species. However, exceptions were evident in walleye pollock Theragra chalcogramma under similar experimental conditions, as fish avoided lower temperatures, but showed little avoidance of higher light, except to move more often into colder water in stratified conditions. Also walleye pollock did not feed in cold water and often became disoriented and unable to return to warmer water (Olla \& Davis 1990, Sogard \& Olla 1993). Younger walleye pollock had a greater tendency to avoid colder water and a lesser tendency to form groups compared with older fish. These age effects were not clearly evident for Pacific cod. Atlantic cod Gadus morhua (Perry \& Neilson 1988, Claireaux et al. 1995) and haddock Melanogrammus aeglefinus in the field (Aglen et al. 1999, Stensholt et al. 2002) avoided higher light and colder water and were attracted to food in patterns of response similar to those observed of Pacific cod.

Vertical movements of Pacific cod in response to changing light, temperature, and food conditions were consistent with previous models for DVM. These results suggest a pattern of vertical distribution that can be tested using observations of field conditions and fish distributions. For example, Pacific cod may respond to increasing light associated with time of day or diminished cloud cover by moving deeper and then adjusting depth according to local temperature, food, and predator distributions. Concurrent measurements of all these factors are necessary for definitive hypothesis testing. A study of tagged Pacific cod showed that fish were generally near the bottom, but were higher in dark conditions than in daylight (Nichol et al. 2007). However, the vertical distribution patterns of these fish were highly variable, suggesting that other factors were interacting with the effects of light. Current speed may also be important, as Pacific cod tended to move towards the bottom when current speed increased and upwards when current decreased (T. Tripp pers. comm.). In co-occurring juvenile populations, haddock followed the tidal cycle, moving upward in the water column as current speed decreased and downward as current increased, while Atlantic cod followed the light cycle, remaining near the bottom during the day and moving upward during the night (Perry \& Neilson 1988). Although these patterns of vertical movement appeared to follow current speed or light conditions, they were attributed to movement of prey, which, in turn, was controlled by current speed or light. The present laboratory study of Pacific cod did not include consideration of several factors that may be important for control or modification of DVM (e.g. dark conditions, predators, physiological state, or gradients of hydrostatic pressure, salinity, current speed, or $\mathrm{O}_{2}$ concentration). Future field studies of Pacific cod DVM should make every effort to measure important environmental and physiological factors concurrently to aid in modelling and interpreting DVM patterns.

The formation of fish groups (shoaling or schooling) can be important for understanding DVM patterns and their possible effects on fish feeding and interactions with predators, as well as on fish surveys and management. In the present study, grouping behaviour changed in the presence of new stimuli presented by changing conditions. Pacific cod group formation was most strongly increased by the presence of food and inhibited by switching to cold water. The inhibition of Pacific cod feeding and group formation in cold water suggests that predator avoidance and fishing gear operations (herding or bait attraction) would also be initially impaired when fish move into cold water and this could be tested in laboratory and field experiments. Grouping was important in other gadoids. Grouping behaviour increased the probability of finding food in juvenile walleye pollock (Baird et al. 1991, Ryer \& Olla 1992), and older fish showed a stronger tendency to group (Sogard \& Olla 1993). Atlantic cod found food more frequently while in groups (Brawn 1969), and cod in groups were associated with pelagic zooplankton prey by expanding and contracting groups in response to foraging activity (DeBlois \& Rose 1995). Grouping behaviour in Atlantic cod and Greenland cod Gadus ogac was important for predator evasion and was modified by interactions of density dependence and habitat quality (Laurel et al. 2004). Previous habitat experience controlled the ability for Atlantic cod to adapt to new habitats by altering grouping behaviour (Salvanes et al. 2007). The effects of experience on grouping may have important implications for feeding and predator evasion as fish move into new environments during DVM or ontogenetic changes in habitat. Fishing operations may also be altered as the effectiveness of baited fishing gear is controlled in part by grouping behaviour (social facilitation) and temperature (Stoner 2004). 
Future study of DVM patterns and their control will be important components for modelling and understanding Pacific cod behaviour, growth, habitats, and fisheries recruitment, and for interpreting fishery surveys to reduce bias. Observations of environmental conditions, physiological states, and behaviour should be made concurrently in the field to assist in the testing and interpretation of observed DVM patterns. These studies can also contribute to a more complete understanding of the interactions among fish condition, experience, and responses to environmental factors that control DVM in gadoids.

Acknowledgements. We thank C. Ryer and B. Laurel for collections of fish, and P. Iseri, S. Haines, and H. Reinhard for excellent technical support. B. Laurel and A. Stoner provided valuable reviews of the manuscript. Fish research was conducted using practices prescribed by the American Fisheries Society-Guidelines for the Use of Fishes in Research (www. fisheries.org/afs/policy.html; accessed 11 November 2009).

\section{LITERATURE CITED}

Abookire AA, Duffy-Anderson JT, Jump CM (2007) Habitat associations and diet of young-of-the-year Pacific cod (Gadus macrocephalus) near Kodiak, Alaska. Mar Biol 150:713-717

Aglen A, Engås A, Huse I, Michalsen K, Stensholt BK (1999) How vertical fish distribution may affect survey results. ICES J Mar Sci 56:345-360

Arnold GP, Walker MG (1992) Vertical movements of cod (Gadus morhua L.) in the open sea and the hydrostatic function of the swimbladder. ICES J Mar Sci 49:357-372

Baird TA, Ryer CH, Olla BL (1991) Social enhancement of foraging on an ephemeral food source in juvenile walleye pollock, Theragra chalcogramma. Environ Biol Fishes 31: 307-311

Brawn VM (1969) Feeding behaviour of cod (Gadus morhua). J Fish Res Board Can 26:583-596

> Ciannelli L, Bailey KM (2005) Landscape dynamics and resulting species interactions: the cod-capelin system in the southeastern Bering Sea. Mar Ecol Prog Ser 291: $227-236$

Claireaux G, Webber DM, Kerr SR, Boutilier RG (1995) Physiology and behaviour of free-swimming Atlantic cod (Gadus morhua) facing fluctuating temperature conditions. J Exp Biol 198:49-60

Conners ME, Munro P (2008) Effects of commercial fishing on local abundance of Pacific cod (Gadus macrocephalus) in the Bering Sea. Fish Bull 106:281-292

> Cote D, Moulton S, Frampton PCB, Scruton DA, McKinley RS (2004) Habitat use and early winter movements by juvenile Atlantic cod in a coastal area of Newfoundland. J Fish Biol 64:665-679

> DeBlois EM, Rose GA (1995) Effect of foraging activity on the shoal structure of cod (Gadus morhua). Can J Fish Aquat Sci 52:2377-2387

Fiksen Ø, Jørgensen C, Kristiansen T, Vikebø F, Huse G (2007) Linking behavioural ecology and oceanography: larval behaviour determines growth, mortality and dispersal. Mar Ecol Prog Ser 347:195-205
Hicks CR (1982) Fundamental concepts in the design of experiments. Holt, Rinehart and Winston, New York

Hobson VJ, Righton D, Metcalfe JD, Hays GC (2007) Vertical movements of North Sea cod. Mar Ecol Prog Ser 347: $101-110$

Laurel BJ, Gregory RS, Brown JA, Hancock JK, Schneider DC (2004) Behavioural consequences of density-dependent habitat use in juvenile cod Gadus morhua and G. ogac: the role of movement and aggregation. Mar Ecol Prog Ser 272:257-270

Laurel BJ, Stoner AW, Ryer CH, Hurst TP, Abookire AA (2007) Comparative habitat associations in juvenile Pacific cod and other gadids using seines, baited cameras and laboratory techniques. J Exp Mar Biol Ecol 351:42-55

> Laurel BJ, Ryer CH, Knoth B, Stoner AW (2009) Temporal and ontogenetic shifts in habitat use of juvenile Pacific cod (Gadus macrocephalus). J Exp Mar Biol Ecol 377:28-35

Maschner HDG, Betts MW, Reedy-Maschner KL, Trites AW (2008) A 4500-year time series of Pacific cod (Gadus macrocephalus) size and abundance: archaeology, oceanic regime shifts, and sustainable fisheries. Fish Bull 106:386-394

Neilson J, Perry RI (1990) Diel vertical migration of fishes: an obligate or facultative process. Adv Mar Biol 26:115-168

> Neilson JD, Clark D, Melvin GD, Perley P, Stevens C (2003) The diel vertical distribution and characteristics of prespawning aggregations of pollock (Pollachius virens) as inferred from hydroacoustic observations: the implications for survey design. ICES J Mar Sci 60:860-871

> Nichol DG, Honkalehto T, Thompson GG (2007) Proximity of Pacific cod to the sea floor: using archival tags to estimate fish availability to research bottom trawls. Fish Res 86: 129-135

Olla BL, Davis MW (1990) Behavioral responses of juvenile walleye pollock Theragra chalcogramma Pallas to light, thermoclines and food: possible role in vertical distribution. J Exp Mar Biol Ecol 135:59-68

Olla BL, Davis MW, Ryer CH, Sogard SM (1996) Behavioural determinants of distribution and survival in early stages of walleye pollock, Theragra chalcogramma: a synthesis of experimental studies. Fish Oceanogr 5:167-178

> Pálsson Ó, Thorsteinsson V (2003) Migration patterns, ambient temperature, and growth of Icelandic cod (Gadus morhua): evidence from storage tag data. Can J Fish Aquat Sci 60:1409-1423

Perry RI, Neilson JD (1988) Vertical distributions and trophic interactions of age- 0 Atlantic cod and haddock in mixed and stratified waters of Georges Bank. Mar Ecol Prog Ser 49:199-214

Ryer CH, Olla BL (1992) Social mechanisms facilitating exploitation of spatially variable ephemeral food patches in a pelagic marine fish. Anim Behav 44:69-74

- Ryer CH, Lemke JL, Boersma K, Levas S (2008) Adaptive coloration, behavior and predation vulnerability in three juvenile north Pacific flatfishes. J Exp Mar Biol Ecol 359: 62-66

Salvanes AGV, Moberg O, Braithwaite VA (2007) Effects of early experience on group behaviour in fish. Anim Behav 74:805-811

Shimada AM, Kimura DK (1994) Seasonal movements of Pacific cod, Gadus macrocephalus, in the eastern Bering Sea and adjacent waters based on tag-recapture data. Fish Bull 92:800-816

Sogard SM, Olla BL (1993) Effects of light, thermoclines and predator presence on vertical distribution and behavioral interactions of juvenile walleye pollock, Theragra chalcogramma Pallas. J Exp Mar Biol Ecol 167:179-195 
Sogard SM, Olla BL (1996) Food deprivation affects vertical distribution and activity of a marine fish in a thermal gradient: potential energy-conserving mechanisms. Mar Ecol Prog Ser 133:43-55

> Stensholt BK, Aglen A, Mehl S, Stensholt E (2002) Vertical density distributions of fish: a balance between environmental and physiological limitation. ICES J Mar Sci 59: $679-710$

Stoner AW (2004) Effects of environmental variables on fish

Editorial responsibility: Benjamin Ruttenberg,

Palmetto Bay, Florida, USA feeding ecology: implications for the performance of baited fishing gear and stock assessment. J Fish Biol 65:1445-1471 Strand E, Huse G (2007) Vertical migration in adult Atlantic cod (Gadus morhua). Can J Fish Aquat Sci 64:1747-1760 von Szalay PG, Somerton DA, Kotwicki S (2007) Correlating trawl and acoustic data in the eastern Bering Sea: a first step toward improving biomass estimates of walleye pollock (Theragra chalcogramma) and Pacific cod (Gadus macrocephalus). Fish Res 86:77-83

Submitted: April 20, 2009; Accepted: November 9, 2009 Proofs received from author(s): December 15, 2009 